\title{
Social Identity Formation in Higher Education Students and Its Relationship with Attachment Patterns
}

\author{
Emad Mohamad Al-zoubi \\ Associate Professor of Educational Psychology, \\ Al-Balqa Applied University, \\ Princess Rahma University College, Jordan
}

Doi: 10.36941/jesr-2020-0o46

\begin{abstract}
The study aimed to investigate the social identity formation status (achievement, moratorium, foreclosure, and diffusion) and identify the relationship between identity formation and attachment patterns (secure, anxiety, and avoidant). The second aim is to detect differences according to the demographic background of the higher education students (the education year and birth order). The study sample consisted of 203 students enrolled in the Balqa'a applied university in Jordan. Two scales were used to achieve purposes of study the psychological identity status scale and attachment patterns scale. The study outcomes asserted that there is a statistically significant difference in the foreclosure identity status among the first-year and fourth-year students in favor of the first year. Likewise, there are statistically significant differences in the diffusion identity status among the first-year, third-year, and fourth-year students in favor of the first-year students. And there are statistically significant differences in the achievement identity status due to the interaction of the education year and birth order. Moreover, the study results indicated a positive proportional and statistically significant relationship between secure attachment and achievement identity. There is a statistically significant relationship between anxiety attachment and the three formation status of social identity (achievement, foreclosure, and diffusion). And there are statistically significant relationships between avoidant attachment and all formation status of social identity (achievement, foreclosure, and diffusion). These relationships are negative to achievement and moratorium identities and positive to foreclosure and diffusion identities.
\end{abstract}

Keywords: Attachment patterns; Higher education students; Social Identity

\section{Introduction}

The rapid changes in all life aspects increase the significance of social identity formation as one of the psychological and social development aspects; due to the impact of identity formation on the adaption ability of individuals. Adams and Marshall (1996) explained the significance of identity development by the individuals' need to individuality sense and feel affiliated and socially valued. The psychological identity concept acquires the interests of psychological and educational researchers due to the correlation between identity and the individuals' social and cultural contexts. The psychological identity associates with the individual consciousness of social existing, and composing perspective towards himself as a part of this context that induces the feeling of affinity, integrity, and importance in the social construction Once the individual accommodates an identity, he can take decision-related to his life to achieve personal goals and determine life paths; such as 
work, marriage, inhabiting religious, beliefs or political perspectives and identifying beneficiaries (Erikson, 1994).

The psychological identity concept considers a vital issue in psychology. This concept was addressed early by many psychologists mentions Jung, Schilder, Erikson, Freud, and others. At the end of the nineteenth century, James had contributed significantly to the psychological identity when addressed the culture and society within his study of psychological identity. As well, addressing behaviorism in the first half of the twentieth century focuses on observable behavior that contributed to the research of psychological identity.

Erikson (1986) suggested that the formation of psychological identity is the essential development function in the adolescent and young adulthood. Thus, he hypothesized that identity formation bases on advanced evolution that requires interaction among developmental, social, and psychological factors (Waterman, 1982). Congruently, Marcia (1966) enriched the methodological and ideological bases of identity research and introduced three-dimensional perspectives of identity; constructivist, exploration, and behavioral. The constructivist dimension related to the psychological construction of the individual personality comprises the identity aspect, ideological aspect, and relation with others. While the exploration dimension referred to the general description of individual identity aspects (career; religion, values, life patterns, ideologists, relationships with others, and gender role) reflects the internal sense and self-concept of the individual, which expressed by four main statuses. The behavioral dimension of identity demonstrates behaviors indicators of identity, which can be observed and measured in different identity aspects. The research has expanded in this concept.

Cheek and Briggs (1982) added a different perspective of identity by considering the social dimension. Cheek and Briggs cited that identity comprises three dimensions social, personal, and collective aspects. The social identity illustrates the entrenched identity in the general element of selfhood, such as reputation and others' impressions. The personal identity found in the distinctive elements of the individual like values, objectives, self-esteem, and psychological status, while the collective identity comprises all standards and predictions of reference-groups like family, community, religion, and race groups.

Whitbourne (1986) delineated identity depends on Erikson and Marcia's theories. As a mental organized representation of accumulative perceived of selfhood (emotional and unemotional), selftraits, physical traits, and knowledge competencies, which interact together simultaneously. The selfperception is perceived by intimacy, professional events, social activities, and the other individual's experiences.

Berzonsky (2011) presented a recent definition of the identity consolidates the knowledge and social dimensions in the formation of identity. Hence the definition scrutinizes identity as an entry rather than result and process rather than construction. Identity defined as a continuous process of inputs used to mimic different references. Furthermore, they generated the concept of identity pattern, which referred to the set of strategies adopted by an individual. Strategies aim to process information of selfhood and experiences for decision-taking and solve problems purposes comprising coding, process, recognizing, amending. It is a conceptual constructive of knowledge and mental presentations. It is a process of interaction among consciousness and adoption processes related to the social and financial environment.

James Marcia described identity as an internal construction of the self. As this construction grows well, the individual becomes more conscious of his distinction and similarity to others in terms of weakness and strengths. Contrary, if the construction is weak, the individual becomes disordered and depended on external sources for self-assessment (Boulu-Reshef, 2015). Marcia found that exploration and commitment define the status of adolescents' identity formation and classify formation as either diffusion or foreclosure. Diffusion status in which the individual did not experience an identity crisis and had any commitment or social role of determining his identity. Thus both commitment and exploration are at low levels. The foreclosure status in which the individual did not experience an identity crisis, but he commits to believes and values related to significant 
persons such as family and surrounding matures, thus the exploration level is low, while the commitment is high. The moratorium status in which individual advocates higher efforts to explore alternatives to identify identity, thus the exploration is at a high-level corresponding to a bereft commitment. The achievement status in which the individual exposed extensive exploration to acquire higher commitment; therefore, both exploration and commitment are at a high level (Waterman, 1999; Pennington, 2015).

There is a consensus that the diffusion identity state is the lowest state of adaption, while foreclosure and moratorium mediate the adaption rank, and the achievement status is the highest level of maturity and adaption (Waterman, 1999). Tap (1986) described identity as a set of standards and systems of consciousness and feelings. It is an internal feeling represented by the loneliness feeling, affinity, belonging, value, independence, and confidence.

The core of social identity links to the individual perceived membership in groups, which supports identity formation. Therefore, the formation process depends on the social comparative in the groups as social category and age and out-groups as a model of standards (Tajfel, 1981). The educational concepts asserted that the optimal identity formation is the one that experiences enriched ritualization, which provided valuable perception to investigate the identity transformations during adulthood and achieved affinity between psychological and social aspects (Taylor, 2013). The psychological identity is not enclosed or constant, but it is an endless transformational and renewable structure developing gradually during adultescents since the end of development may be either achievement or foreclosure. Consequently, it can be concluded that the psychological identity has two main components; the self-personal component and the social component (Klimstra et al., 2010).

The formation of psychological identity is not spontaneous. It endures stages and timely evolving starts from childhood to the maturity passing adulthood. It is a dynamic vital process to reach relative stability. The sense of identity influenced by the continuity of life events such as roles, standings, relationships with others, and external events (Kroger, 2007). Edmon (2005) deliberated five processes of identity formation, which are; The first is the distinguish process that occurs when a child can determine his body's feelings, tendencies, and emotions to be able to distinguish between himself and external world. The second process is mimicking, which occurs once the individual accommodates others' models and mimics it. The third process is narcissistic prizing erected on the emotional supports perceived from surroundings particularly family. The fourth process is the acquisition process composes the self-consciousness progression and stability feelings over time, regardless of the variety of roles and experiences. The fifth process is the achievement process exhibited in the individual's openness to future achievements and projects. Similar to Bosma and Kunnen (2008) asserted that continuous supports and encouragement of reference groups, particularly family, facilitates identity formation and increases its stability.

The adulthood and early youth are crucial stages of psychological identity formation because identity formation is an essential requirement for developing during this phase; it is representing the transformation of adultescent personality toward independence, which is a requirement for the normal development in the later stages (Meeus, 1996). The social and cultural interaction is a significant factor of identity formation in which the socialization gains a distinct consideration in the psychological identity formation. The individual learns the social role from the others who are dealing with them like parents, brothers, peers, and teachers. However, the correlation degree with them determines the affinity sense and identity formation. If the correlation decreases, the affinity will deficit and identity evanesce. Contrary, the higher correlation increases the individual knowledge of social roles and identity determination that develops with their socialization, and its features exhibit obviously when an individual accomplishes his social role (Kroger, 2007).

It is observed that the tendency of recent studies concerns the psychological and social context of identity formation components; hence, it compels researchers to speculate the status and disorders of identity formation rather than conducts only the identity term. The Identity, as a psychological component, may exposure negative influential circumstances either to personal or surroundings 
related factors. The main affected is the culture-social dimension of identity because of the recent social variation and relationship instability among groups. There are many factors form identities such as friendships, awareness of social genre roles, the relationship between gender, and entertainment (Coleman \& Hendry, 1990; Hiley et al., 2007).

One of the social factors that influence psychological identity is attachment. To Ainsworth and Bowlby (1991), attachment is an individual propensity to create intimate relationships with particular persons in his surroundings. Lafreniere et al. (2008) defined attachment as strong emotional bonds induce happiness, pleasure, and security when remains close to the care provider and anxiety and annoyance when the individual separated from the care provider. Kim (2005) defined attachment as a psychological bond of feelings and interaction among adults in the form of intimacy or friendship. In the current study, attachment defined as psychological energy encourages the individual to establish emotional and intimate bonds with the individuals that support him emotionally and incorporeally.

The literature mentioned three patterns for attachment, secure attachment, anxious attachment, and avoidant attachment. The secure attachment reflects self-confidence, confidence in others, and tendencies to an intimate relationship in general. One the other hand, the anxious attachment exhibits an emotional contradictions condition, extensive care of relationships seeking proximity, and fear of rejections and loss of their affinity. The avoidant attachment exhibits uncomfortable in close relationships thus seeks to avoid closeness relationships and fear of inefficiency in the intimacy (Ainsworth et al., 1987; Feeney, 2008).

Enormous studies conducted identity formation of vast ages as the same diverse studies investigated the relationships between identity formation and various variables like attachment patterns variable examined by Berman et al. (2006). Berman et al. deliberated the relationship between identity formation and the romantic attachment of higher education students with various ethnicities. This study emphasized differences among identity formation due to attachment patterns. It found that the foreclosed identity has the lowest relationship with both avoidances and anxiety scores compared to diffused and achieved identities and moratorium groups respectively. Furthermore, the study asserted relationship presence between identity formation and romantic attachment style only among college students, while the relationship evanesces among high school students.

Similarly, McNamara Barry et al. (2009) found that there is a positive correlation between achievement identity and the quality of the romantic relationship. Contrary to the quality of friendship, which negatively correlated to the achievement identity, driven that social relationships exposure differentiated influences during adulthood development.

Kerpelman et al. (2012) studied the indirect and direct effects of identity style and romantic attachment on identity commitment. The study found that both identity style and romantic attachment have direct associations to identity commitment. There is not any moderation effect of gender, race, and relationship status on the association between identity style and romantic attachment and identity commitment. And there are statistical differences in identity styles and romantic attachments due to gender and race variables. Furthermore, the study revealed the direct effects of identity style and avoidant attachment on the identity commitment and the indirect effect of romantic attachment (avoidant and anxiety) on identity commitment.

Mollasaeidi, Arefi, and Joshoghani (2015) studied the correlation between identity styles and romantic attachment of undergraduate students in Iran, reached 1250 male and female students. The study found that both informational and diffusion styles are the optimal predictors to the avoidant attachment, while the avoidant identity is the best predictor of anxiety attachment.

This study aims to provide an integrative vision about the social identity formation of the late adulthood and early mature individuals and determine the relationship of identity formation and the attachment patterns (secure, anxiety, avoidant) considering the educational year and birth order in the Arabian cultural frame in Jordan. According to the researcher's knowledge, this study may be the only study that conducts the identity formation and its relationship to attachment patterns in terms of educational year and birth order in the social Arabian environment. 


\subsection{Limitation}

The study includes a limited number of students enroll the princes Rahma university college/ Balqa'a applied university in the first semester of 2019-2020 educational year. Consequently, the generalizing of study results limited to the study population and similar populations. Moreover, the study results generalizing limited in the context of validity and reliability of the study tools.

\subsection{Hypotheses}

- Hi: There are statistically significant differences among the mean score of the social identity formation in the level of achievement, diffusion, foreclosure, and moratorium due to educational year, birth order, and its interaction

- H2: There is a statistically significant relationship between the social identity formation in the level of (achievement, diffusion, foreclosure, and moratorium) and the attachment patterns (secure, anxiety, avoidant).

\section{Method}

\subsection{Participants}

The study sample consists of 103 male and female students enrolled in the prince Rahma university college/ Balqa'a applied university in the first semester of 2019/2020.

\subsection{Instruments}

\subsubsection{Social Identity status Scale for adulthood and early mature}

The study adopted the self-reporting scale of "Objective Measure of Ego Identity Status" developed by Adams (1989) based on Marcia's (1966) and Eriokson's (1968) perspectives. This scale was translated by Alghamdi (2007) into the Arabic language. The self-reporting scale consists of 64 items, distributed equally for two dimensions; ideologic identity and social identity, in which both divided into four levels and four domains. In the current study, the social identity part was only adopted, which consists of 32 items distributed among four identity statuses (achievement, diffusion, foreclosure, and moratorium) and four domains (friendship, sexual role, gender relationship, and recreation). The original version of the scale has an acceptable degree of the reliability and validity, as well the translated version of the scale has acceptable reliability using the split-half test on the social identity, which scored (o.73), achievement level scored (0.79), moratorium scored (o.79), foreclosure scored (0.77), and diffusion scored (0.76). Furthermore, the scale has a significant internal consistency. Hence, the correlation coefficients (distinguish coefficient) of items range between 0.32 to 0.46 . In this study, two approaches used to examine the scale reliability, split-half test in which the reliability coefficient scored (o.74), and internal consistency approach in which the correlation coefficient scored (o.77). Both scores are accepted to the current study purposes.

\subsubsection{Scale of attachment patterns}

The study adopted the attachment patterns scale for maturities developed by Abugazallah and Jaradat (2009). This scale was previously applied to the higher education students and earned an acceptable reliability and validity scores. The scale consists of 20 items distributed on three dimensions: secure attachment that assesses the positive degree of perceptions about self and others. Second is the anxious attachment that assesses the negative degree of self-perception and the degree of positive perceptions of others. The third is the avoidant attachment that assesses the degree of 
positive self-perception and negative perception of others.

To evaluate the reliability of the scale, the correlation coefficient was calculated utilizing the Pearson correlation coefficient for items, the overall score of related dimensions, and the overall score of the scale. The correlation coefficient between items and the overall score of related dimension falls within the range of (0.45-0.70). While the coefficient ranged between $0.49^{-0.69}$ is the coefficient of correlation between items and the overall scale score, which all are statistically significant at level $(\mathrm{a}=0.05)$. Accordingly, the scale is reliable since it measures what supposed to measure. To ensure validity, the internal consistency coefficient was measured (Cronbach's alpha) for all three dimensions scored (o.79; o.85; o.81), which are acceptable validity scores.

\section{Results and Discussion}

H1: There are statistically significant differences among the mean score of the social identity formation in the level of achievement, diffusion, foreclosure, and moratorium due to educational year, birth order, and its interaction.

Table 1: MANOVA Test Results of the Mean Score of The Social Identity Formation in the Level of Achievement, Diffusion, Foreclosure, and Moratorium due to Academic Year and Birth Order and Its Interaction.

\begin{tabular}{llcccccc}
\hline Source & $\begin{array}{l}\text { Identity Status } \\
\text { (Dependent Variable) }\end{array}$ & SS & df & MS & F & P & (n2) \\
\hline Academic Year & Achievement & 197.202 & 3 & 65.734 & 2.615 & .052 & .039 \\
Wilk's $\Lambda=0.87$ & Moratorium & 68.548 & 3 & 22.849 & .850 & .468 & .013 \\
Sig.=0.09 & Foreclosure & 337.437 & 3 & 112.479 & 2.803 & .041 & .042 \\
& Diffusion & 368.855 & 3 & 122.952 & 2.851 & .039 & .043 \\
Birth order & Achievement & 87.620 & 2 & 43.810 & 1.743 & .178 & .018 \\
Wilk's $\Lambda=0.958$ & Moratorium & 3.083 & 2 & 1.541 & .057 & .944 & .001 \\
Sig.=0.419 & Foreclosure & 138.376 & 2 & 69.188 & 1.724 & .181 & .018 \\
& Diffusion & 68.648 & 2 & 34.324 & .796 & .453 & .008 \\
Academic Year * Birth order & Achievement & 413.023 & 6 & 68.837 & 2.739 & .014 & .079 \\
Wilk's $\Lambda=0.836$ & Moratorium & 242.160 & 6 & 40.360 & 1.501 & .180 & .045 \\
Sig.=0.081 & Foreclosure & 273.759 & 6 & 45.626 & 1.137 & .342 & .034 \\
Error & Diffusion & 270.631 & 6 & 45.105 & 1.046 & .397 & .032 \\
& Achievement & 4801.11 & 191 & 25.137 & & & \\
& Moratorium & 5137.07 & 191 & 26.896 & & & \\
Corrected Total & Foreclosure & 7665.69 & 191 & 40.135 & & & \\
& Diffusion & 8236.21 & 191 & 43.122 & & & \\
& Achievement & 5520.39 & 202 & & & & \\
& Moratorium & 5426.46 & 202 & & & & \\
& Foreclosure & 8482.60 & 202 & & & & \\
\hline
\end{tabular}

According to the results shown in table no. (1) above there are statistically significant differences of foreclosed and diffusion identities due to the educational year with small effect size $((\eta \mathbf{\eta})=4.2 \%),($ $(\mathbf{\eta} 2)=4.3 \%)$, respectively. And there are statistically significant differences of identity formation status due to the interaction between the educational year and birth order with small effect size $((\mathbf{\eta 2})=7.9 \%)$ (cohen,1988). To recognize the sources of difference in both foreclosure and diffusion identities due to the educational year, the Tukey test was used. The results are shown in the following table. 
Table 2: Tukey Test Results To Define The Differences Sources of Both Foreclosure and Diffusion identities due to Academic year

\begin{tabular}{lllccc}
\hline \multicolumn{1}{l}{ Identity Status } & Academic Year & First Year (29.1) & Second Year (27.5) & Third Year (28.7) & Fourth Year (24.3) \\
\hline \multirow{3}{*}{ Foreclosure } & First Year & - & -1.6545 & 3.0982 & $4.75^{2} 8^{*}$ \\
& Second Year & - & - & 1.2333 & .4212 \\
& Third Year & - & - & - & -4.3316 \\
& Academic Year & First Year (50.3) & Second Year (27.7) & Third Year (25.4) & Fourth Year (23.5) \\
\multirow{2}{*}{ Diffusion } & First Year & - & -2.8131 & $4.8337^{*}$ & $6.9737^{*}$ \\
& Second Year & - & - & 4.1606 & 4.937 \\
& Third Year & - & - & - & $2.915^{-}$ \\
\hline
\end{tabular}

It is observed that from table no. (2) that the foreclosure identity is statistically significantly higher of the first-year students compared to the fourth-year students, as well the diffusion identity is statistically significantly higher of first year students compared to the third and fourth-year students. However, the related results of the achievement identity status due to interaction effect of the educational year and birth order together visualized by figure no. (1) shows that the level of achievement identity status is inconstant, varies according to the variation of the educational year. Further, the instability of achievement identity varies according to the variation of birth order.

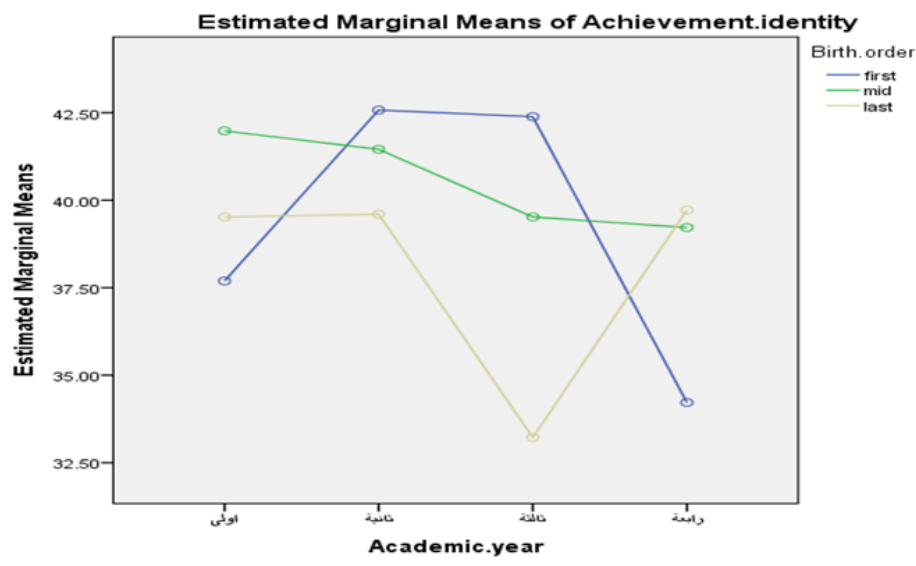

Figure 1: The Interaction Effect of Academic Year and Birth Order on the Achievement Identity Status

H2: There is a statistically significant relationship between the social identity formation in the level of (achievement, diffusion, foreclosure, and moratorium) and the attachment patterns (secure, anxiety, avoidant).

Table 3: Pearson Correlation Coefficient Between the social identity formation and the Attachment Patterns

\begin{tabular}{lccc}
\hline Identity Status/ Attachment Pattern & Secure & Anxiety & Avoidant \\
\hline Achievement & $.273^{* *}$ & .061 & $.386^{* *}$ \\
Moratorium & .050 & $.373^{* *}$ & $.487^{* *}$ \\
Foreclosure & .071 & $.586^{* *}$ & $.201^{* *}$ \\
Diffusion & .003 & $.422^{* *}$ & $.321^{* *}$ \\
\hline
\end{tabular}

*. Correlation is significant at the o.05 level (2-tailed).

**. Correlation is significant at the o.o1 level (2-tailed). 
It is revealed from table no.(3) that there is a statistically significant positive correlation between secure attachment and achievement identity status. Similar to a positive significant correlation between the anxiety attachment and all social identity formation status (diffusion, foreclosure, and moratorium). But the relationship between anxiety and moratorium is weak. However, the relationship is relatively strong among the related case of anxiety and foreclosure and diffusion status. Moreover, there is a statistically significant correlation between avoidant attachment and all status of social identity formation (achievement, diffusion, foreclosure, moratorium). It is negatively relative strength correlations between avoidant attachment and both achievement and moratorium identities. Contrary, the relation is weakly positive between avoidant attachment and foreclosure and diffusion identities.

\section{Conclusion and Recommendations}

The study aimed to investigate the social identity formation in the achievement, diffusion, foreclosure, and moratorium levels according to educational year, birth order variables, and its interaction. Additionally, the study aimed to define the relationship between the status of social identity formation (achievement, diffusion, foreclosure, and moratorium) and attachment patterns (secure, anxiety, and avoidant) among higher education students.

In terms of the first hypothesis related to the differences in the social identity formation degree in the achievement, diffusion, foreclosure, and moratorium levels due to the educational year, birth order, and the interaction between both. The results asserted the presence of statistically significant differences in the foreclosure identity between first-year students and fourth-year students in favor of first-year students. Likewise, there are statistically significant differences in the diffusion identity formation among the first-year, third-year, and fourth-year students in favor of the first-year student. Despite the rationality of the results, but the result indication is not good for psychological and social development at this age. The diffusion and foreclosed identities of the first-year students explained by the acquiring source of their social experiences, which is limited to their relationships with relative persons and family, and their inefficiency of creating affinity, and independence by their owns. Generally, the overcoming of diffusion and foreclosure identity status requires a huge effort and advanced social interaction and engagement. In other hand, the third and fourth-year students overcame the foreclosure and diffusion status because both categories exposure to advanced social engagement and interaction due to the spent years at university, which supports and promotes social and psychological components formed identity like friendship, sexual role, gender relationship, and recreation (Coleman \& Hendry, 1990; Smetana et al., 2006; Hiley et al., 2007). This result coincides with Marcia's reasoning, who indicated that the advanced social identity statuses (achievement and moratorium) exhibit a strong commitment formed after exploration for a time interval of the spectrum of experiences and attempts. This driven that adultescents start transformed toward achieved identity, per they get old as emphasized by Waterman $(1982,1999)$.

In terms of the results related to the achievement identity status due to the interaction between educational year and birth order, the results illustrated that the level of achievement identity degree is unstable and varying according to the educational year varying, and this instability state varies according to the variation of birth order in the family. These results agreed to studies mentioned that the identity status is an instable dynamic state, and the variation could be either growing or descending, such as (Marcia, 1980; Waterman, 1982, 1993; Kroger, 2007). This result interpreted by the personal traits related to the birth order in the family and the cultural frame in the Jordanian Arabic community, which manages children differently according to their birth order.

The second hypothesis study related to the relationship among the social identity formation (achievement, diffusion, foreclosure, and moratorium) and attachment patterns (secure, anxiety, and avoidant). The related results emphasized the positive significant relationship between secure attachment and achieved identity as expected. Hence, the individual who has a secure attachment positively comprehend his self and others and seeking to get close to others in his social context such as parents, brothers, relatives, and instructors. This closure proportionally influences his awareness of 
social roles, and his choices of social interactions vigorously correlated to identity development, which serves students to reach more mature identities (achievement). In the same context, results asserted the statistical significance relationships of anxiety attachment and social identity formation (diffusion, foreclosure, and moratorium), which was relatively weak with the moratorium identity, and relatively strong with foreclosure and diffusion identities. The contradictory norm of anxiety attachment can explain the relationship, since the anxiety attachment exaggerates the relationship with others, fear of rejection, seeking continuity close to others, isolation, and loss of partner intimacy. The likelihood to have foreclosure or diffusion status increases as increasing in the individual exhibition of these behaviors. On other hands, if the individual extremely committed to his social context, political, religious, and profession perceptions of family and references groups, the likelihood of moratorium identity formation will increase as introduced by previous studies like (Mollasaeidi, Arefi and Joshogha, 2005; Kerpelman et al., 2012; Berman et al., 2006; and McNamara et al., 2009), which cited the relationship between identity formation and anxiety attachment.

Moreover, the study outcomes affirmed the negative relationship between avoidant attachment and achievement and moratorium identities formation and the positive relationship between avoidant attachment and foreclosure and diffusion identities formation. This can be explained by the discomfort to relationship intimacy and fear of inefficiency in social relationship contexts, which exhibited in anxiety attachment. Because the avoidant attachment makes the individual isolated from social context induces foreclosure, affinity deficits, and the lack of exploration abilities in social interaction that normally associated with identity developments. Once the individual negatively considers his social context and positively considers his self, then the social context will endure worse commitment model of regulation and social and political ideologies which obstructs the normal development of social identity, increases the likelihood of diffusion and foreclosure identities formation, and decreases the likelihood of achievement and moratorium identities formation. These results coincide with (Mollasaeidi, Arefi, and Joshoghani, 2015; Kerpelman et al., 2012; McNamara et al., 2009, and Berman et al., 2006) studies that emphasized the relationships between identity formation and avoidant attachment.

According to the study outcomes, the researcher suggests a set of recommendations. These recommendations aim to promote social identity development at the end of adulthood and mature higher education stage. The higher educational institutes have to provide systematic and unsystematic programs to boost the development of social identities and reduce the formation of diffusion identity during the higher education years. This recommendation regards the relationship between identity formation, attachment patterns, and educational years as revealed in the current study and previous studies. However, the program must be diverse and developmental to support the normal development of the students' social identities and prevent descending state of identity development. Furthermore, therapeutic programs are recommended to treat abnormal social identity development. It is essential to conduct further studies about social identity and its relationship to various variables.

\section{References}

Abugazallah, M., and Jaradat, A. (2009). Adults' attachment patterns and their relationship to self-esteem and loneliness. The Jordanian Journal of Educational Sciences, 5, 1, 45-57.

Adams, G.R. (1989). Objective measure of ego identity status: a reference Manual. (Available from Adams, G. R., University of Guelph, Guelph, Ontario, Canada).

Adams, G.R., and Marshall, S. (1996). A developmental social psychology of identity: Understanding the person in context. Journal of Adolescence, lo, 1 - 14.

Ainsworth, M., Blehar, M., Waters, E., and Wall, S. (1987). Patterns of attachment: A Psychological study of the strange situation. Hillsdale, NJ: Erlbaum.

Ainsworth, M., and Bowlby, J. (1991). An ethological approach to personality development. American Psychological, $46,333-341$.

Alghamdi, H. A. (2007). Objective measure of the identity of the ego, a codified version of the male and young men in the western region of Saudi Arabia. Umm Al-Qura University, the Institute of Scientific Research, Educational and psychological research center. 
Berman S.L., Weems C.F., Rodriguez E.T., and Zamora I.J. (2006). The relation between identity status and romantic attachment style in middle and late adolescence. Journal Adolescence, 29: 737-748 .

Berzonsky, M.D. (2011). A social-cognitive perspective on identity construction. In S.J. Schwartz, K.Luyckx, and V.L. Vignoles (Eds.), Handbook of identity theory and research (pp.55-76). NewYork: Springer.

Bosma, H. A., and Kunnen, E. S. (2008). Identity-in-context is not yet identity development-in-context. Journal of Adolescence, 31, 2, 281-289. doi:10.1016/j.adolescence.2008.03.001.

Boulu-Reshef, B. (2015). "Towards a Personal Identity Argument to Combine Potentially Conflicting Social Identities". Review of Social Economy. 73(1): 1-18.

Cheek, J. M., and Briggs, S. R. (1982). Self-consciousness and aspects of identity. Journal of Research in Personality, 16, 401-408.

Cohen, J. (1988). Statistical power analysis for the behavioral sciences. Hillsdale, NJ: Erlbaum.

Coleman, J.C, and Hendry, L. (1990)." The Nature of Adolescence" Second edition, London EC4P ${ }_{4} \mathrm{EE}$, published in the USA and Canada by Routledge.

Edmon, M (2005). Psychology of self and group identity, Dunod, Paris.

Erikson, E. (1968). Identity: Youth and crisis. New York: W. W. Norton Company.

Erikson, E.(1994). Identity: Youth and crisis. NewYork: W.W. Norton Company. (Original work pub-lished in 1968).

Feeney, J.A. (2008). Adult romantic attachment: Developments in the study of couple relationships. In J. Cassidy and P.R. Shaver (Eds.), Handbook of attachment: Theory, research, and clinical applications (2nd ed., pp. 456-481). New York: Guilford Press.

Hiley S.E., Coatsworth, J.D., Darling, N; Cumsille, P., and Ranieri, S. (2007) "Gender differences in the self-defining activities and identity experiences of adolescents and emerging adults". Journal of Adolescence, 30, 2, $251-269$.

Kerpelman, J.L., Pittman, I.F., Cadely, H.S., Tuggle, F.J., Harrel-Levy, M.K., and Adler-Baeder, F.M. (2012). Identity and intimacy during adolescence: Connections among identity styles, romantic attachment and identity commitment. Journal of Adolescence, 35: 1427-1439.

Kim, Y. (2005). Emotional and cognitive consequences of adult attachment: The mediating effect of the self. Personality and Individual Differences, 39, $913-923$.

Klimstra, T. A., Hale, W. W., Raaijmakers, Q. A. W., Branje, S. J.T., and Meeus, W. H. J. (2010). Identity Formation in Adolescence: Change or Stability?. Journal of Youth and Adolescence, 39, 150-162.

Kroger, J. (2007). Presidential address: The status of identity. Paper presented at the 14th Annual Conference of the Society for Research on Identity Formation, George Washington University, Ashburn, Virginia.

Lafreniere, M.A.K., Jowett, S., Vallerand, R.J., Donahue, E.G., and Lorimer, R. (2008). Passion in Sport: On the Quality of the Coach-Athlete Relationship. Journal of Sport and Exercise Psychology, 30, 541-560.

Marcia, J. E. (1966). Development and validation of ego-identity status. Journal of Personality and Social Psychology, 3 , 551-558. doi:10.1037/hoo23281.

Marcia, J. E. (1980). Identity in adolescence. In J. Adelson (Ed.). Handbook of adolescent psychology. New York: Wiley.

McNamara CM., Madsen SD., Nelson LJ., Carroll JS., and Badger, S. (2009). Friendship and romantic relationship qualities in emerging adulthood: Differential associations with identity development and adulthood criteria. Journal of Adult development,16, 209-22.

Meeus, W. H. J. (1996). Studies on identity development in adolescence: An overview of research and some new data. Journal of Youth and Adolescence, 25, 569-598. doi:10.1007/BFo1537355.

Mollasaeidi1, S., Arefi, M., and Joshoghani, A. (2015) The Relationship between Identity Styles and Romantic Attachment among college students. International Journal of Psychology and Behavioral Research, 4(1), 9-14.

Pennington, M. (2015). Teacher identity in TESOL: A frames perspective. In Y. L. Cheung, S. Ben Said and K. Park (Eds), Advances and current trends in language teacher identity research (pp. 16-30). London: Routledge.

Smetana, J., Barr, N., and Metzger, A (2006). " Adolescent Development in Interpersonal and Societal Contexts ". Journal Annual Review of Psychology, 57, 255-284.

Tajfel, H. (1981). Human groups and social categories: Studies in social psychology. New York, NY: Cambridge University Press.

Tap, P. (1986). Identity and social changes, Privat, Toulouse.

Taylor, F. (2013). Self and identity in adolescent foreign language learning. Bristol: Multilingual Matters.

Waterman, A. S. (1982). Identity development from adolescence to adulthood: An extension of theory and a review of research. Developmental Psychology, 18, 342-358. doi:10.1037/oo12-1649.18.3.341.

Waterman, A. S. (1999). Identity, the identity statuses, and identity status development: A contemporary statement. Developmental Review, 19, 591-621. doi:10.1006/drev.1999.0493.

Whitbourne, S.K. (1986). Personality development in adulthood and old age: Relationships among identity style, health, and well-being. Annual Review of Gerontology and Geriatrics, 7, 189-216. 